\title{
Análise de sinais fenotípicos no reconhecimento precoce da Síndrome de Rubinstein-Taybi
}

\author{
Yara Guedes Machado de Matos ${ }^{1}$ \\ Eliane Costa Passos ${ }^{2}$ \\ Acácia Fernandes Lacerda de Carvalho ${ }^{3}$ \\ Lília Maria Azevedo Moreira ${ }^{4}$
}

\section{Resumo}

Este trabalho teve como objetivo verificar uma possibilidade de combinação de traços fenotípicos, incluindo dermatóglifos, que possa ser utilizada como um método de triagem para a identificação de possíveis portadores da Síndrome de Rubinstein-Taybi. Isso poderia permitir o encaminhamento para tratamentos precoces, que venham melhorar o desenvolvimento intelectual, a qualidade de vida e o convívio social, especialmente daqueles portadores que dependem da saúde pública e que não dispõem de condiçōes para exames mais dispendiosos e especializados.

Palavras-chave: Síndrome de Rubinstein-Taybi - sinais fenotípicos e método de triagem; dermatóglifos.

\section{INTRODUÇÃO}

A Síndrome de Rubinstein-Taybi (SR-T) foi descrita pela primeira vez em 1963 por Dr. Jack H. Rubinstein e Dr. Hooshang Taybi, que fizeram um relatório sobre sete crianças, com polegares e halux largos e grandes, anomalias faciais características e retardo mental. Não parece haver predileção por sexo e, de acordo com Korosue (1998), é menos encontrada em negros.

A incidência da SR-T é de 1 em cada 300.000 nascidos vivos na população geral e de 1 em cada 300 crianças com retardo mental. É listada no Catálogo de Doenças Mendelianas de McKusick (www.ncbi.nlm.nih.gov/entrez/ query.fcgi? $\mathrm{db}=\mathrm{OMIM}$ ) como uma patologia autossômica dominante, com penetrância variável. Em 1992, foi evidenciada a localização do gene responsável pela síndrome na banda cromossômica 16p13.3, sendo atualmente considerada uma síndrome de microdeleção, que envolve uma série de genes contíguos (SUGAYAMA et al., 2004).

A Síndrome de Rubinstein-Taybi é caracterizada pela presença de microcefalia, fronte olímpica e fontanela anterior ampla, posição antimongolóide das fendas palpebrais, epicanto, nariz adunco e com raiz larga, estrabismo, sobrancelhas espessas, orelhas com implantação

\footnotetext{
${ }^{1}$ Especialista em Citogenética Humana pela UCSAL. Professora do Colégio Estadual Raphael Serravalle. Salvador - BA.

${ }^{2}$ Especialista em Citogenética Humana pela UCSAL.Professora do Colégio Estadual Henriqueta Catharino. Salvador - BA.

${ }^{3}$ Coordenadora do Curso de Especialização em Citogenética. UCSAL Salvador - BA.

${ }^{4}$ Professora Titular de Genética. Departamento de Biologia Geral. Instituto de Biologia da UFBA. Salvador - BA.
}

Correspondência para / Correspondence to:

Yara Guedes Machado de Matos

Rua Guillard Muniz, s/n - Itaigara.

41.810-110. Salvador - Bahia - Brasil.

E-mail: yaragmm@hotmail.com. 
baixa, palato em ogiva, discreto retrognatismo (FIGURA 1). Acrescente-se ainda a presença de polegares engrossados, podendo ser observadas falanges com desvio radial na articulação interfalangiana, às vezes clinodactilia, polidactilia, superposição dos dedos dos pés. Criptorquidia também pode ser observada (WIEDEMANN; FUNZE; DIBBERMANN, 1992).

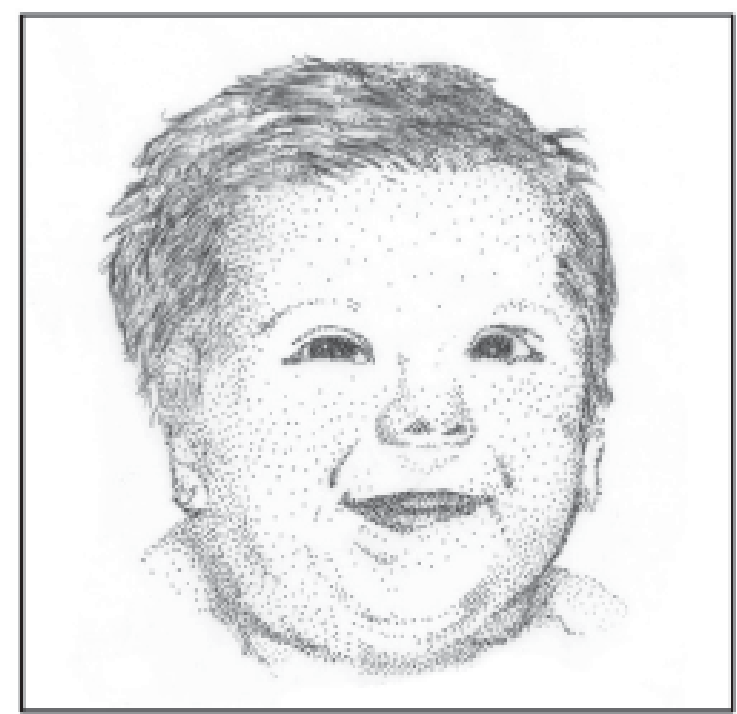

Figura 1- Desenho representativo de criança com aspecto crânio-faciais freqüentes na S.de Rubinstein-Taybi.

Quando recém-nascidos, os afetados apresentam altura e peso normais ou próximos aos verificados em crianças normais; mas, em adultos, é comum a estatura baixa, assim como um atraso na maturação óssea. Anomalias vertebrais, como falta de fusão do arco da primeira vértebra cervical, escoliose, espondilolistese cervical e espina bífida oculta são alterações que podem ocorrer. A maioria dos portadores aprende a engatinhar e a sentar entre o primeiro e o segundo ano de vida. A marcha em geral é rígida, devido a alterações do sistema neurológico (KOROSUE, 1998).

Alguns portadores da SR-T apresentam anomalias congênitas no sistema circulatório, como defeito no septo ventricular e atrial, estenose da aorta, estenose pulmonar e hipoplasia do coração. Recém nascidos com obstrução severa de fluxo sanguíneo do coração para o corpo necessitam de procedimentos cirúrgicos de emergência (KOROSUE, 1998).

Alterações na morfologia dentária, estão presentes em $90 \%$ dos casos. O cirurgião-dentista deve estar atento não só para o tratamento odontológico do paciente, mas também para possíveis comprometimentos sistêmicos. Podem ser observados dentes em excesso ou em falta, bem como alterações de tamanho e cáries. A boca freqüentemente apresenta-se pequena. Caretas ou um sorriso peculiar é notado na maioria dos pacientes (KOROSUE, 1998).

As várias alterações faciais fazem com que alguns pacientes mostrem manifestações ligadas à área otorrinolaringológica, como obstrução nasal, infecções de repetição das vias aéreas superiores, otites, sinusites, amigdalites, inclusive com incidência de perdas auditivas de graus variados. As manifestaçōes fonoaudiológicas que mais se destacam são as dificuldades na aquisição da linguagem oral e as alterações no tônus da musculatura perioral, que já podem ser percebidas durante a tentativa de amamentação, como dificuldade de sucção e deglutição (MARTINS; BUENO; FIORAVANTI, 2003).

Quanto ao desenvolvimento de linguagem e o desempenho escolar, evidenciam-se dificuldades na aquisição da linguagem e na alfabetização. As crianças falam as primeiras palavras entre o segundo e o terceiro ano, ou até mais tarde. Acredita-se que o principal fator responsável pelas limitaçôes é a alta incidência de retardo mental presente nos portadores. Há também um grave comprometimento da atenção e da memória (MARTINS; BUENO; FIORAVANTI, 2003).

Estudos em alguns portadores da SR-T demonstraram hiperatividade, temperamento amigável e agressivo num padrão cíclico compatível com episódio bipolar de psicose maníaco-depressiva, com sintomas que melhoram significativamente com terapia medicamentosa (HELLINGS et al., 2002).

Dermatóglifos de pacientes com SR-T mostram numerosos traços raros. Os dermatóglifos são configuraçōes digitais e palmares 
fáceis de coletar e observar, que estão sob controle genético (RODRÍGUEZ CUENCA, 1999). O período crítico da formação de rugas começa no feto, aproximadamente em torno de três meses de idade, é concluído somente após o $6^{\circ}$ mês pré-natal, quando as dobras glandulares estão completamente formadas, e após a secreção das glândulas sudoríparas e a queratinização já terem começado. Nesse momento, a configuração sobre a superfície da pele começa a refletir o padrão da camada inferior. As saliências inferiores $\mathrm{da}$ epiderme correspondem às saliências das rugas da camada germinativa, e cada ruga epidérmica é formada abaixo de uma dobra glandular. A embriogênese das rugas epidérmicas dos pés é idêntica à das mãos, embora cada etapa ocorra duas a três semanas mais tarde (MULVIHILL; SMITH, 1969).

Pregas de flexões representam a ligação da pele com estruturas subjacentes e, embora não pertençam estritamente ao sistema dermatoglífico, estão normalmente incluídas na rotina da análise desses traços. São formadas durante o início da vida intra-uterina e, por isso, podem ser influenciadas por diversos fatores que causam alteraçôes no desenvolvimento do embrião (SCHAUMANN; ALTER, 1976). Na Síndrome de Rubinstein-Taybi, os referidos autores destacam o conjunto de sinais listados abaixo e apresentados na Figura 2.

Este trabalho teve como objetivo examinar, na associação entre traços fenotípicos na Síndrome de Rubinstein-Taybi, uma combinação que possa ser utilizada como um método de triagem na identificação de possíveis portadores dessa alteração.

\section{MATERIAIS E MÉTODO}

A metodologia utilizada na investigação foi observacional, com o estudo de caso, para registro das características fenotípicas, utilizando-se fichas de anamnese e tabelas com sinais patognomônicos.

Como parte do estudo fenotípico, foram analisados dermatóglifos coletados com instrumental composto de rolo de borracha, placa de

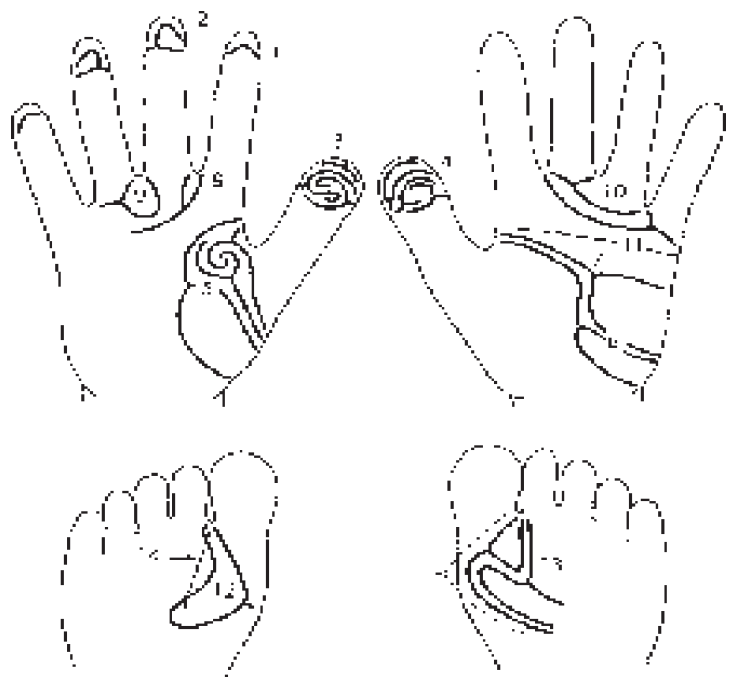

Figura 2- Desenhos esquemáticos das principais características dermatoglíficas da S. de Rubinstein-Taybi (Adaptada de SCHAUMANN; ALTER,1976).

Nota: 1- Freqüência aumentada de arcos; 2- Presilhas radiais voltadaspara outros dedos exceto o segundo; 3 - Trirrádio apical nopolegar e pododáctilo; 4 - Padrōes duplos nos polegares; 5 Padrôes tenar / $\mathrm{I}^{1}$ aumentados em freqüência, tamanho e complexidade; 6 -Presilha ulnar como padrão predominante na área hipotenar, associado; 7 -Trirrádio axial distal e onsequenteaumento no ângulo atd; 8 - Freqüência aumentada de padróes $\mathrm{I}^{2}$; 9 Frequiência aumentada nos padrões $\mathrm{I}^{3} ; 10$ - Trirrádio $c$ deslocado; 11- Frequiência aumentada de linha única transversa palmar; 12Presilha distal longa, rara e distorcida na áreahalucal; 13-Combinação presilhas distal e fibular $\left(\mathrm{L}^{\mathrm{d}} / \mathrm{L}^{\mathrm{f}}\right)$ naárea halucal plantar; 14Prega plantar profunda na primeira área interdigital -"Sandal crease"

zinco e mistura de tinta guache preta, atóxica, com glicerina, na proporção de 2:1. As impressões foram coletadas em folhas de papel sulfite.

\section{RESULTADOS}

\section{Ilustração Clínica}

Criança de sexo masculino, cinco anos, nascida de gravidez a termo, parto normal, com peso de $3.100 \mathrm{~g}$. Quando mamou pela primeira vez, vomitou e passou a manifestar dificuldades na alimentação. Aos três meses, não sustentava o pescoço. Andou aos dois anos e ainda não apresenta fala compreensível. Apresentava estrabismo, já corrigido com tratamento. Foi realizada intervenção cirúrgica para correção de criptorquidismo e retirada de dedos extras no pé. 
As características fenotípicas atuais incluem: baixa estatura $(95 \mathrm{~cm})$, escoliose, marcha insegura, fácies típico, fronte abaulada, nariz aquilino, palato em ogiva, hipoplasia do maxilar inferior, cílios longos, sobrancelhas cheias, posição antimongolóide das fendas palpebrais, polegares e hálux grossos e prega simiesca na mão esquerda.

Tem comportamento dócil, carinhoso, alegre, gosta de música e dança. Freqüenta escola regular e apresenta deficiência mental moderada. Realiza intervenções com terapeuta ocupacional, fonoaudióloga e fisioterapeuta.

\section{Estudo dos dermatóglifos}

A análise das impressões de mãos e pés (FIGURA 3) evidenciou diversas características incomuns.

Mão esquerda: Padrão duplo no dedo I (verticilo duplo); presilha radial $\left(\mathrm{L}^{\mathrm{r}}\right)$ no dedo II; presilha radial no dedo III; presilha ulnar $\left(\mathrm{L}^{\mathrm{u}}\right)$ no dedo IV; presilha ulnar $\left(\mathrm{L}^{\mathrm{u}}\right)$ no dedo V; padrão presilha na região tenar; região hipotenar negativa; atd $\mathrm{t}^{\prime \prime \prime} 83^{\circ}$; $\mathrm{I}_{2}$ campo aberto; $\mathrm{I}_{3}$ presilha distal $\left(\mathrm{P}^{\mathrm{d}}\right) ; \mathrm{I}_{4}$ presilha distal $\left(\mathrm{P}^{\mathrm{d}}\right)$; presença de trirrádio c e linha transversa única.

Mão direita: Presilha ulnar no dedo I; $\operatorname{arco}(\mathrm{A})$ no dedo II; presilha ulnar $\left(\mathrm{L}^{\mathrm{u}}\right)$ no dedo III; presilha ulnar $\left(\mathrm{L}^{\mathrm{u}}\right)$ no dedo IV; $\operatorname{arco}(\mathrm{A})$ no dedo V; padrão presilha na região tenar; Região hipotenar negativa; atd $\mathrm{t}^{\prime \prime} 74^{\circ} ; \mathrm{I}_{2}$ campo aberto (sem padrã); $\mathrm{I}_{3}$ Negativo; $\mathrm{I}_{4}$ Presilha distal $\left(L^{\mathrm{d}}\right)$; presença de linha Sydney transicional pouco diferenciada.

Pés: Uma prega profunda na primeira área interdigital, "Sandal crease" (Prega sandália); presilha distal distorcida na área halucal.

\section{Características patognomônicas}

O probando descrito neste estudo apresentou como características típicas da Síndrome de Rubinstein-Taybi: hálux e polegares largos e grandes, posição antimongolóide das fendas palpebrais, palato alto, atraso no desenvolvimento psicomotor, baixa estatura, outros dedos da mão também largos, alterações do sistema dentário, criptorquidia, hirsutismo, pés planos,

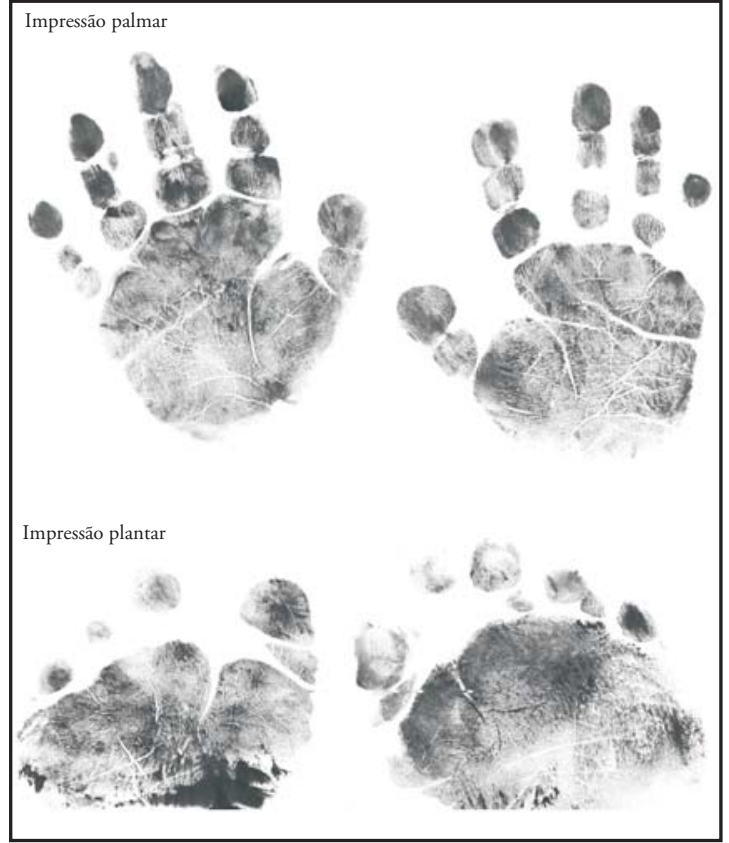

Figura 3- Dermatóglifos do probando.

nariz aquilino com o septo nasal estendido além das asas do nariz, sobrancelhas grossas, altamente arqueadas, marcha insegura, estrabismo e a "Sandal crease" nos dois pés.

\section{DISCUSSÃO}

A análise realizada permitiu elaborar um sistema de pontuação de acordo com as características fenotípicas de maior frequiência e importância (JONES, 1998; KOROSUE, 1998; MARTINS; BUENO; FIORAVANTI, 2003; SCHAUMANN; ALTER, 1976). A Tabela 1 apresenta 19 características às quais foi atribuída pontuação de 1 a 3 , conforme a maior freqüência do sinal em afetado, seguindo-se a proposta de Sugayama (2002). Ao final, somamse os pontos, cujo total deve ser superior a 22 . O probando em estudo totalizou 27 pontos, considerado típico para a SR-T. Dessa maneira, o teste do FISH só seria indicado apenas para aqueles com valores inferiores a esse valor ou com suspeita duvidosa. 
Tabela 1 - Sistema de pontuação para identifica-ção fenotípica da SR-T

\begin{tabular}{l|c|c|c}
\hline \multicolumn{1}{c|}{ Características } & Incidência $(\%)$ & Pontos & Probando \\
\hline Presença de hálux e polegares largos e grandes & 100 & 3 & 3 \\
\hline Posição antimongolóide das fendas palpebrais & 100 & 3 & 3 \\
\hline Palato em ogiva & 100 & 3 & 3 \\
\hline Atraso no desenvolvimento psicomotor & 100 & 3 & 3 \\
\hline Baixa estatura & 94 & 3 & 3 \\
\hline Atraso na maturação óssea & 94 & 3 & - \\
\hline Alteraçóes no sistema dentário & 90 & 2 & 2 \\
\hline Outros dedos da mão também largos & 87 & 2 & 2 \\
\hline Crânio pequeno & 84 & 2 & - \\
\hline Orelhas de implantação baixa & 84 & 2 & - \\
\hline Criptorquidia & 79 & 1 & 1 \\
\hline Estrabismo & 79 & 1 & 1 \\
\hline Infecçóes respiratórias & 78 & 1 & - \\
\hline Marcha insegura & 76 & 1 & 1 \\
\hline Hirsutismo & 75 & 1 & 1 \\
\hline Pés planos & 72 & 1 & 1 \\
\hline Sobrancelhas grossas altamente arqueadas & 69 & 1 & 1 \\
\hline Nariz aquilino & 68 & 1 & 1 \\
\hline Prega sandália & 60 & 1 & 1 \\
\hline TOTAL & & 35 & 27 \\
\hline
\end{tabular}

\section{CONCLUSÕES}

A análise de sinais fenotípicos, incluindo-se os dermatóglifos, pode ser utilizada com bons resultados para auxiliar o diagnóstico de vários distúrbios de origem genética, como a Síndrome de Rubinstein-Taybi, com o fim de racionalizar o uso de métodos como as análises cromossômicas completa ou parcial.

Os achados da anamnese e a aplicação do sistema de pontuação, diante de um quadro fenotípico sugestivo da S. Rubinstein-Taybi, trazem uma contribuição importante, no sentido de indicar o teste do FISH somente para aqueles casos poucos definidos.
As metodologias de reconhecimento precoce, de acordo com a análise fenotípica, como proposto neste trabalho, podem contribuir para que os portadores de S. de Rubinstein-Taybi tenham a possibilidade de melhoria de suas condiçōes de vida e de desenvolvimento. Esse reconhecimento favorece também uma posterior adaptação social, de modo que, mais tarde, o convívio social e intelectual do portador possa ser melhor aproveitado, com oportunidade de estudo, trabalho e realização de outras atividades comuns.

\section{Phenotypic features analyses to recognize precociously the Rubinstein-Taybi Syndrome}

\section{Abstract}

The intention of this project is to verify, in the association between the phenotypic features of RubinsteinTaybi Syndrome, a combination possibility which can be used as a screening method to identify possible 
carriers of this syndrome as soon as possible. This can provide conditions for treatments which may improve their living, socializing and learning, especially for those carriers who depend on the public health and do not afford expensive and specialized exams.

Keywords: Rubinstein - Taybi Syndrome - Phenotypic features - selection method; dermatoglyphics.

\section{REFERÊNCIAS}

GABRIELE S.; GUIZI, M. Rubinstein-Taybi syndrome: study of dermatoglyphics and differential diagnosis. Minerva. Pediatr., Torino, v.27, n.14, p.879-886, 1975.

HELLINGS, J.A. et al. Psychopathology, GABA, and the Rubinstein-Taybi Syndrome: a review and case study. Am. J. Med. Genet., New York, v.114, n.2, p.190-195, 2002.

JONES, K.L. Padrões reconhecíveis de malformaçôes congênitas de Smith. Tradução Marcos Ikeda. 5.ed. São Paulo: Manole, 1998.

KOROSUE, A.L. Syndrome de RubinsteinTaybi. 1998. 92 p. Monografia (Curso de Fisioterapia)- Universidade Bandeirante de São Paulo, São Paulo, 1998.

MARTINS, R.H.G.; BUENO, E.C.; FIORAVANTI, M.P. Síndrome de Rubinstein-

Taybi: anomalias físicas, manifestações clínicas e avaliação auditiva. R.. Bras. Otorrinolaringol., Porto Alegre, v.69, n.3, 2003.

MULVIHILL, J.J.; SMITH, D.W. The genesis of dermatoglyphics. J. Pediatr., St. Louis, v.75, p.579, 1969.
RODRÍGUEZ CUENCA, J.V. Los Chibchas: pobladores antiguos de los Andes orientales: la evidencia dermatoglífica. Bogotá: Colciencias, 1999.

SCHAUMANN; B.; ALTER, M. Dermatoglyphics in medical desordens. New York: Springer-Verlag, 1976.

SUGAYAMA, S.M.M. Etiologia da S. de Rubinstein-Taybi. Disponivel em: <http:// www.artsbrasil.org.brlfase $2 /$ materia.asp? $p=118>$ Acesso em: 21 jul. 2004.

SUGAYAMA, S.M.M. et al. Proposta de sistema de pontuação para diagnósticoclínico da Síndrome de Williams-Beuren. In: CONGRESSO BRASILEIRO DE GENÉTICA CLÍNICA., 14., 2002, Ribeirão Preto. Anais... Ribeirão Preto: SBGC, 2002. p.69

WIEDEMANN, H.R.; KUNZE, J.; DIBBERMAN, $\mathrm{H}$. Atlas de síndromes clínicas dismórficas. Tradução Hildegard Thimann Buckup. 3.ed. São Paulo: Manole, 1992. 